Comparison of the serious injury pattern of adult bicyclists, between South-West

Netherlands and the State of Victoria, Australia 2001-2009

Pınar Yılmaz ${ }^{\mathrm{a}, \mathrm{b}}, \mathrm{MSc}$, Medical student

E-mail: pnrylmz@live.nl

Belinda J. Gabbe ${ }^{\text {b,c }}$, Physio(Hons), MBiostat, MAppSc, PhD, Senior Research Fellow

E-mail: belinda.gabbe@monash.edu

Francis T. McDermott ${ }^{\mathrm{d}}$, MBBS,FRACS,FRCS(Eng), FACS, Honorary Professor, The Alfred, Monash University and Honorary Professorial Fellow, Austin Health, The University of Melbourne

E-mail: $\underline{\text { mcdf@ozemail.com.au }}$

Esther M.M. Van Lieshout ${ }^{\mathrm{e}}, \mathrm{PhD}$, research coordinator Trauma Surgery

E-mail: e.vanlieshout@erasmusmc.nl

Pleunie P.M. Rood ${ }^{\mathrm{a}}$, MD, PhD, Emergency Physician

E-mail: p.rood@erasmusmc.nl

Terrence M. Mulligan DO, MPH ${ }^{\mathrm{f}, \mathrm{g}}$, Assistant Professor in Emergency Medicine, University of Maryland School of Medicine, Department of Emergency Medicine, Director of International Emergency Medicine Program / Extraordinary Senior Lecturer, Stellenbosch

University, Division of Emergency Medicine

E-mail: tmulligan@umem.org 
Peter Patka ${ }^{\mathrm{a}}, \mathrm{MD}, \mathrm{PhD}$, Trauma Surgeon, Head Department of Emergency Medicine

E-mail: p.patka@erasmusmc.nl

Peter A. Cameron ${ }^{\text {b,ch }}$, MB BS, MD, FACEM, Head, Prehospital and Emergency Trauma Group, Monash University; Academic Director, Emergency and Trauma Centre, Alfred Hospital; Head, Victorian State Trauma Registry; and Associate Director, National Trauma Research Institute

E-mail: peter.cameron@monash.edu

${ }^{a}$ Department of Emergency Medicine, Erasmus MC, University Medical Centre Rotterdam, Rotterdam, The Netherlands

${ }^{\mathrm{b}}$ Department of Epidemiology and Preventive Medicine, Monash University, Melbourne, Australia

${ }^{\mathrm{c}}$ National Trauma Research Institute, The Alfred, Melbourne, Australia

${ }^{\mathrm{d}}$ Department of Surgery, Monash University, Melbourne, Australia, Department of Surgery, The University of Melbourne, Australia

${ }^{\mathrm{e}}$ Department of Surgery-Traumatology, Erasmus MC, University Medical Centre Rotterdam, Rotterdam, The Netherlands

${ }^{\mathrm{f}}$ University of Maryland School of Medicine, Department of Emergency Medicine, Director of International Emergency Medicine Program, Baltimore, Maryland, USA

${ }^{\mathrm{g}}$ Stellenbosch University, Division of Emergency Medicine, Extraordinary Senior Lecturer.

Cape Town, South Africa

${ }^{\mathrm{h}}$ Emergency and Trauma Centre, The Alfred, Melbourne, Australia 
Corresponding author: Department of Epidemiology and Preventive Medicine, Monash

University, The Alfred, Commercial Road, Melbourne, Victoria, 3004, Australia. Tel.: +61 3 9903 0581; fax: +61399030576.

E-mail: peter.cameron@med.monash.edu.au (P.A. Cameron) 


\title{
Comparison of the serious injury pattern of adult bicyclists, between South-West Netherlands and the State of Victoria, Australia 2001-2009
}

\begin{abstract}
Background: Head injury is the leading cause of death and long term disability from bicycle injuries and may be prevented by helmet wearing. We compared the pattern of injury in major trauma victims resulting from bicyclist injury admitted to hospitals in the State of Victoria, Australia and South-West Netherlands, with respective high and low prevalence of helmet use among bicyclists.
\end{abstract}

Methods: A cohort of bicycle injured patients with serious injury (defined as Injury Severity Score >15) in South-West Netherlands, was compared to a cohort of serious injured bicyclists in the State of Victoria, Australia. Additionally, the cohorts of patients with serious injury admitted to a Dutch level 1 trauma centre in Rotterdam, the Netherlands and an Australian level 1 trauma centre in Melbourne, Australia were compared. Both cohorts included patients admitted between July 2001 and June 2009.

Primary outcome was in-hospital mortality and secondary outcome was prevalence of severe injury per body region. Outcome was compared using univariate analysis and mortality outcomes were also calculated using multivariable logistic regression models.

Results: A total of 219 cases in South-West Netherlands and 500 cases in Victoria were analysed. Further analyses comparing the major trauma centres in each region, showed the percentage of bicycle-related death was higher in the Dutch population than in the Australian ( $n=45(24 \%)$ vs $n=13(7 \%) ; P<0.001)$. After adjusting for age, mechanism of injury, GCS and head injury severity in both hospitals, there was no significant difference in mortality (Adjusted Odds Ratio 1.4; 95\% confidence interval=0.6, 3.5). 
Patients in Netherlands trauma centre suffered from more serious head injuries (Abbreviated Injury Scale $\geq 3)$ than patients in the Australian trauma centre $(n=165(88.2 \%)$ vs $n$ $=121(62.4 \%) ; P<0.001)$. The other body regions demonstrated significant differences in the AIS scores with significantly more serious injuries (AIS $\geq 3$ ) of the chest, abdominal and extremities regions in the Australian group.

Conclusion: Bicycle related major trauma admissions in the Netherlands trauma centre, and in South-West Netherlands had a higher mortality rate associated with a higher percentage of serious head injuries compared with that in the Australian trauma centre and the State of Victoria.

Key words: Bicycle; head injury; helmet; emergency department (350 words) 


\section{Introduction:}

Bicycles are a popular form of transport and recreation worldwide. In the Netherlands, there has been an increase in the number of hospital admissions from bicycle injuries, despite high levels of road safety and possibly a decreasing incidence of traffic fatalities ${ }^{1}$. The Netherlands (population approximately 16.5 million) sees an estimated 67,000 presentations of bicyclist casualties at the Emergency Departments (ED) per year and 8,000 hospital admissions ${ }^{2}$. A third of these patients are diagnosed with head injuries and approximately 190 deaths occur per year ${ }^{3}$. Head injury is the leading cause of death and long-term disability from bicycle injury $^{1,4}$. Both the Netherlands and Australia are witnessing a significant number of traffic deaths due to bicycle injuries each year (185 vs 31 in 2009) $)^{5,6}$. Bicyclist participation rates differ in both countries with bicyclists comprising $1.6 \%$ of all commuter journeys in Australia and $27 \%$ in the Dutch population ${ }^{7}$.

In several countries, head injuries resulting from bicycle use have prompted mandatory helmet legislation. Australia was the first to adopt this law in 1990 following research that suggested that helmet use reduced the incidence of head injury ${ }^{8-13}$. A number of countries including New Zealand, several states and localities of the United States and Canada followed $^{14}$, however, in the Netherlands helmet use is required for competitive cyclists only ${ }^{15}$.

As a result, the prevalence of helmet wearing in the Netherlands is low (0.1-5\%) compared to Australia (70-90\%) where helmet wearing is mandatory in all states and territories ${ }^{10,15}$. It is difficult to design studies to test the effectiveness of injury prevention strategies at a population-level. Randomised controlled trials may be considered unethical or not feasible, particularly where there is legislation directing the intervention. Population based, prospective cohort studies are expensive, especially if exposure to risk is adequately documented and likely to have confounders that are difficult to adjust for ${ }^{14,16-18}$. 
Retrospective cohort studies using existing data are a useful alternative to gain some perspective on the problem.

Given the differences in helmet wearing rates and bicycle culture ${ }^{19-21}$ between The Netherlands and Australia, the aim of this study was to compare the pattern of bicycle injury for admitted patients with serious trauma (Injury Severity Score [ISS ${ }^{22}$ ] >15) between South West Netherlands (where helmet use is low) and Victoria State (where helmet use is high), over the period 2001-2009. 


\section{Methods:}

\section{Study Setting}

This study was a retrospective cohort study for the period July 2001- June 2009. Data on bicycle-related casualties were extracted from the dataset of Trauma Centre South-West Netherlands (TCSWN) in Rotterdam, The Netherlands, and from Victorian State Trauma Registry (VSTR) in Australia. All patients had an ISS $>15$.

The cohort of South-West Netherlands was compared to the cohort of Victoria, Australia. Both the Netherlands trauma centre in Rotterdam and the Australian trauma centre in Melbourne are level 1 trauma centres. In an attempt to exclude referral bias in our study, we have additionally made a comparison between patients admitted to both trauma centres (Figure 1).

Trauma Centre South-West Netherlands Trauma Registry

The Netherlands trauma centre in Rotterdam is the level 1 trauma centre for the SouthWestern region of The Netherlands serving a population of 2.5 million inhabitants (350 major trauma patients per year). Rotterdam has approximately 590,000 residents $^{23}$. The TCSWN Trauma Registry is a hospital based registry. Data was collected from all patients admitted to Netherlands trauma centre, the only level-1 trauma centre in the region, including all major trauma patients that were transported from the region to the level 1 trauma centre by Helicopter Emergency Medical Service (HEMS). Criteria for the HEMS to transport patients to Netherlands trauma centre were Revised Trauma Score (RTS) $<11$, or one of the following (suspected) injuries: penetrating injury to head, thorax and/or abdomen; two or more unstable 
fractures of femur and/or humerus; unstable pelvic fractures; flail chest; complete neurological deficit of one extremity; amputation proximal to wrist or ankle; chemical trauma; or body temperature $<32{ }^{\circ} \mathrm{C}$. The TCSWN database included the same variables as used in the Major Trauma Outcome Study (MTOS) ${ }^{24}$ database (age, Glasgow Coma Scale [GCS] score, Revised Trauma Score [RTS], mechanism of trauma and details of injuries). Patients that died at the scene or on arrival at the ED, and transfers of patients with injuries requiring intensive care unit (ICU) admission to other hospitals were not included.

\section{Victorian State Trauma Registry}

The VSTR is a population-based trauma registry, which has been collecting data on all major trauma patients in Victoria since July 2001. Victoria has a population of 5.5 million residents with Melbourne having just under 4 million citizens ${ }^{25}$. The registry methods have been

published previously ${ }^{26}$. The VSTR was established to monitor and evaluate the state's regionalized, inclusive trauma systems. The registry provides data on all phases of acute care from the pre-hospital setting to acute hospital for patients defined as major trauma. All acute hospitals in Victoria contribute data to the registry. The Australian trauma centre is a level 1 trauma centre with approximately 1200 major trauma admissions per year from both metropolitan and regional areas.

A patient is defined as "major trauma" if they meet any of the following criteria: death due to injury; an ISS of more than 15; an ICU stay longer than 24 hours requiring mechanical ventilation and urgent surgery. 


\section{Study Patients}

All patients, who presented with bicycle-related injuries registered by the participating trauma registries with an ISS >15 and a date of injury between July 2001 and June 2009 were included for analyses. A bicycle injury was defined as an injury of a person with a bicycle in motion or no motion with any physical damage due to any cause. A serious head injury was defined as any head injury with Abbreviated Injury Scale (AIS ${ }^{27}$ ) severity score of 3 and above, indicating intracranial injury or complex skull fracture. Patient charts with incomplete data for primary and secondary outcome measures, bicycle trauma mechanisms and patient characteristics were excluded ( $n=41$ for TCSWN and $n=112$ for VSTR).

\section{Analysis}

Extracted variables included age, gender, helmet use, mechanism of injury, GCS on arrival at ED, ISS, AIS in the body regions: Head/Neck, Face, Chest, Abdominal/Pelvic contents and Extremities/Pelvic girdle, discharge from hospital, and in-hospital mortality. Descriptive statistics were performed to summarize the profile of patients across the hospitals (Netherlands trauma centre vs Australian trauma centre) and the trauma populations (TCSWN vs VSTR). Percentages, mean and standard deviation (SD), or median and interquartile range (IQR) were calculated to describe continuous variables. For categorical variables the frequencies were reported. Comparisons across the settings were performed using chi-square tests for categorical variables, and either independent sample $t$-tests or Mann-Whitney $U$ tests depending on the distribution of the data. 
As a prognostic factor for injury outcome, the AIS was assigned to each injury and the overall injury severity was calculated with the ISS. The GCS on arrival at the ED was categorized into three groups; severe (GCS 3-8), moderate (GCS 9-12) and mild (GCS 13$15)$.

To assess the adjusted risk of mortality between trauma centres, a multivariable logistic regression model was generated. Variables demonstrating a significant difference $(P<0.05)$ between the trauma centres, and mortality, on univariate analyses were included in the multivariable logistic regression model as potential confounders of the association between trauma centre and outcome. Adjusted odds ratios [(AOR) (95\% confidence interval (CI)] were computed to estimate the strength of association between each trauma setting and mortality. All analyses were performed using the Statistical Package for the Social Sciences (SPSS) for Windows (version 18.0) and Stata MP (Version 11.2). A $P$ value $<0.05$ was considered significant for tests.

\section{Ethics approval}

This study was conducted according to the principles of the Declaration of Helsinki (October 2008) and in accordance with the Medical Research Involving Human Subjects Act (WMO). The privacy and confidentiality of personal information of research subjects was protected by de-identifying patients. The study received approval from the local Medical Ethics Committee of the Netherlands trauma centre, Rotterdam, The Netherlands. The VSTR has ethics approval from the Human Research Ethics Committee at Monash University and all participating health services $(n=138)$. 


\section{Results:}

During the study period from 2001 to 2009,219 bicycle-related cases were registered by the TCSWN registry and 500 cases were registered by the VSTR. For comparison of adult major trauma cases ( $\geq 15$ years), there were 187 for Netherlands trauma centre and 194 patients for Australian trauma centre (Figure 1).

Patient profile for Netherlands trauma centre vs Australian trauma centre

The patient profile differed between the trauma populations for most variables. Table 1 shows the Netherlands trauma centre had an older population with more females compared to the Australian. Most injuries occurred in the older age category $\geq 60$ years in Rotterdam, whereas the Australian trauma centre had higher percentages in the middle aged group (40-59 years) and more male bicycle users admitted with serious injury, particularly in the younger aged group.

Both hospitals recorded collisions of bicycles with motorized vehicles as the main mechanism of injury. However the Australian trauma centre patients had more falls from bicycles compared with patients from the Netherlands. Helmet usage was reported more frequently in the Australian than the Netherlands trauma centre. Glasgow coma scores were greater at the Netherlands trauma centre than the Australian. The vital signs on arrival at the ED were comparable in both centres. 


\section{Mortality}

The association between Netherlands trauma centre vs Australian trauma centre and inhospital mortality is detailed in Table 1 . The highest mortality rate was seen in patients with serious injuries (AIS $\geq 3$ ) in the head region in Netherlands trauma centre when compared to the Australian (93\% vs $88 \%$ ) and there were more in-hospital deaths ( $n=45(24.1 \%)$ vs $n=$ $13(6.7 \%))$ for the Netherlands trauma centre. The unadjusted odds ratio for death for patients in the Netherlands trauma centre was significantly higher than for patients in the Australian (OR 4.4; 95\% CI: 2.3, 8.5) and was similar to the regional comparison TCSWN vs VSTR (OR 4.3; 95\% CI: 2.7, 8.9). The setting of the hospitals, age, mechanism of injury, GCS and head injury severity were considered potential confounders. However, adjusted for these confounders the Netherlands trauma centre patients did not show significantly elevated odds of death compared with patients from the Australian (AOR 1.4; 95\% CI: 0.6, 3.5). The adjusted odds ratio comparing mortality between Netherlands trauma centre and Victorian State data remained significantly elevated 3.3 (95\% CI: 1.4, 7.7).

Serious head injury (AIS $\geq 3)$ and injury to other body regions

While the ISS was identical in both populations, patients in Netherlands trauma centre had more serious head injuries (AIS $\geq 3$ ) than patients in the Australian (Netherlands trauma centre vs Australian trauma centre $(n=165[88.2 \%]$ vs $n=121[62.4 \%] ; P<0.001)$. The GCS on arrival at the ED also varied between populations with almost twice the percentage of severe head injuries (GCS 3-8) in Netherlands trauma centre compared to the Australian (Table 1). Fewer patients scored an AIS 0 for the head region at Netherlands trauma centre than Australian trauma centre. Figure 2 shows a histogram of bicycle injuries with the AIS 
scores of the head and neck region aligned with the groups of patients who survived or died in Netherlands trauma centre. The number of deaths increased with higher AIS scores. In the Australian trauma centre data (Figure 3), the death rate was lower with fewer deaths from GCS 3-5 head injuries. The other body regions demonstrate significant differences in the AIS scores with serious injuries (AIS $\geq 3$ ) of the chest, abdominal and extremities regions more common in the Australian group (Table 1).

Comparison between Trauma Centre South-West Netherlands Trauma Registry and Victorian State Registry data

Further analyses of regional data for the State of Victoria, including paediatric patients demonstrated a similar injury pattern to the Australian trauma centre data in respect to age, gender and helmet wearing rates. However, falls were the main mechanism of injury in the State of Victoria when compared with the Australian trauma centre. Again, there were more seriously head injured patients in the South-West Netherlands group relative to VSTR than serious injuries to other body regions ( $n=190$ [86.7\%] vs $n=295$ [59.0\%]; $P<0.001$ ). And in-hospital deaths were more than three times more frequent in data for South-West Netherlands $(n=51(23.3 \%)$ vs $n=33(6.6 \%))$. 


\section{Discussion:}

This study demonstrated a higher proportion of serious head injuries in major trauma patients involved with bicycle-car collisions in Netherlands trauma centre than Australian trauma centre, and a corresponding higher mortality risk in Netherlands trauma centre. Differences existed in geography, population, trauma admissions and organization of the health care system and are discussed below however, the trauma registries collect data using standard international scoring systems.

The difference in pattern of injuries for patients with major trauma between the regions in our study is marked. In contrast a study by Kingma et al in the Netherlands on the etiology and long-term effects of bicycle accidents in persons aged 50 years and older showed the majority of injuries were observed in the upper extremities $(28.8 \%)$ and head/face regions $(25.8 \%)^{1}$. However, they did not select major trauma patients and there were mainly minor injuries. In the current study the patients in the Netherlands trauma centre had more serious injuries in the head and neck region than other injuries compared with the Australian. The second most serious injuries were seen in the chest region where the Australian trauma centre had a higher frequency. The Australian group had more serious injuries in all the other body regions except for the face. The study by Sikic et al. ${ }^{4}$ found $51 \%$ of the major trauma cases were injured in the trunk region. This difference in injury patterns could possibly be explained by the high rate of helmet use in Australia.

Bicycle helmets are almost universally recommended as an injury prevention strategy but convincing evidence on their effectiveness has been debated since increased awareness of cycling safety in the early nineties. Several studies have shown that there is likely to be a substantial reduction in head injuries by wearing safety helmets ${ }^{10,11,13,16,17,28-31}$. 
In many countries bicycle crash analysis and the effect of helmet usage are being discussed to identify characteristics that will contribute to preventing cycling injuries and to improve and develop new strategies for decreasing serious injuries. Germany ${ }^{32,33}$ and Scandinavia ${ }^{34-36}$ are leading Europe in analysing follow up data for hospital based bicycle injury patients and their outcomes in association with the prevalence of helmet use.

Interestingly, for the mechanism of injury, the Netherlands trauma centre showed more bicycle accidents due to collision with a motor vehicle compared to Victoria State, raising the question of the impact of designated bicycle paths as a model in traffic infrastructure in the Netherlands. When comparing both trauma centres, collisions associated with motor vehicles were the main mechanism of injury in both the Australian and Netherlands trauma centre patients.

There was a peak in injuries for elderly patients between 70-79 years and for mortality in the Netherlands trauma centre that differed from the Victorian State group. Both countries have a greater number of males as reported in all previous studies. Elderly females in Rotterdam had higher numbers of serious injuries than those in Victoria (16\% vs $0.01 \%$ ) most likely because of higher participation rates reported in Rotterdam. Previous reports of the epidemiology of bicycle injuries by Kingma and colleagues ${ }^{37}$ are in agreement with the high mortality rates that we found in the elderly age groups for the Netherlands. The study by Sikic et al ${ }^{4}$. also supports our findings, using Victorian data which showed that male patients under 55 years were the most injured group and there were few serious injuries above this age. A possible reason for these differences is the 'bicycle culture' in Rotterdam where more children and adolescents use bicycles as transportation to schools and the elderly for short distance transportation. 
Although this study is unique in comparing the pattern of injury in bicyclists in two different populations, there were limitations to the data. Geographically based differences in bicycle use in both countries were not available. Also, an ideal population based study would include all patients with bicycle injuries and not be limited to severely injured hospitalised patients. We compared registry data from two major trauma referral centres in two regional databases. The difference in referral patterns and processes may have resulted in a more biased sample of patients. However, when we compared both Netherlands and Australian trauma centres with the regions (South West Netherlands and Victoria State) we did not find differences in injury patterns.

We used the criterion of ISS $>15$ to ensure all major trauma patients were included, and to maximise similarities between the injured populations across the two registries. The Netherlands trauma centre is the only level-1 trauma centre in the region for 2.5 million people, however it can not be ruled out that some severely injured patients (ISS $>15$ ) were treated in level 2 centres in the regions that were not part of the TCSWN registry. Another potential selection bias was the exclusion of patients identified as dead at the scene or on arrival at the emergency department, as both variables were not available in the databases surveyed.

The participation rates for bicycling in recent years have not been published and thus the incidence of bicycling injuries amongst bicyclists is not possible to calculate. The cities Rotterdam and Melbourne have similarities in being the second largest in each country, however the bicycle culture differs as in the Netherlands bicycling is encouraged from a very young age. In Australia most bicyclists start at an older age and a large part of the population has never been exposed to riding in traffic with a bicycle whereas in the Netherlands most 
motor vehicle occupants are also bicycle riders and aware of the vulnerability of a bicyclist in traffic ${ }^{19,20}$. The bicycle types are different with Australian bicyclists more likely to participate for sport and use special clothing and race or use mountain bicycles for riding long distances in comparison to Dutch bicyclists, mostly casually dressed with city-bicycles and mainly riding short distances. Furthermore the traffic network is different, for example the bicycle lanes in Victoria are a part of the main road (highways included) with speed limits of up to $80-100 \mathrm{~km} / \mathrm{h}$ and rarely form a separate bicycle lane separated from the motorized traffic stream $^{38}$. In the Netherlands, both cars and bicycle riders in the city are not exposed to high speed because of traffic limitations ${ }^{39}$.

Other limitations included missing data in both systems to optimise valid comparisons between the data sets. Accurate data were not available for some important factors including helmet usage and the place of injury. Ideally, one would perform randomized controlled trials in several countries for a defined period of time to include all patient factors prospectively such as environment (season, weather, description of accident, and place of injury), behavioural factors and medical factors with and without helmet usage. Since this is impossible to execute in reality we must rely on observational studies. Improvements to data registries are necessary to make valid and accurate comparisons of complete population based samples and possible international trend analyses in the future. 


\section{Conclusions:}

Bicycle related admissions secondary to major trauma in the Netherlands trauma centre, region South-West Netherlands had a higher mortality rate associated with a higher percentage of serious head injuries compared with bicycle related injured patients in the Australian trauma centre and the Victorian State Registry. Although this study has a number of limitations, the differences in injury profile suggest that many of these head injuries may be preventable by helmet wearing. Better evidence should be developed using population based trauma registries along with detailed injury and exposure data, to ensure optimal injury prevention strategies are enforced. It is essential that we develop a stronger evidence base to target injury prevention efforts and reduce bicycle related morbidity and mortality. 


\section{References}

1. Kingma J, Duursma N, ten Duis HJ. The aetiology and long-term effects of injuries due to bicycle accidents in persons aged fifty years and older. Percept Mot Skills. Dec 1997;85(3 Pt 1):1035-1041.

2. SWOV, Institute for Road Safety Research. Fact sheet: Bicycle helmets. Leidschendam, The Netherlands. October 2009. Available at: http://www.bhsi.org/stats.htm.

3. SWOV, Institute for Road Safety Research. Fact sheet: Bicycle helmets. Leidschendam, The Netherlands. September 2012. Available at:

http://www.swov.nl/rapport/Factsheets/UK/FS Bicycle helmets.pdf.

4. Sikic M, Mikocka-Walus AA, Gabbe BJ, McDermott FT, Cameron PA. Bicycling injuries and mortality in Victoria, 2001-2006. Med J Aust. Apr 6 2009;190(7):353-356.

5. Bureau of Statistics. Cause of death: traffic deaths with bicycle 2009. The Hague/Heerlen, The Netherlands. Updated April 2011. Available at:

http://statline.cbs.nl/StatWeb/publication/?VW=T\&DM=SLNL\&PA=71936NED\&D1=2\&D2= a\&D3=a\&D4=5-14\&HD=110518-0706\&HDR=T\&STB=G1;,G2，G3.

6. Bureau of Infrastructure, Transport and Regional Economics (BITRE). Road Deaths Australia 2009 Statistical Summary. Canberra ACT, Australia. 2010. Available at: http://www.bitre.gov.au/statistics/safety/files/database.pdf.

7. Bureau of Infrastructure. Cycling Infrastructure for Australian Cities. March 2009. Available at:

http://www.infrastructureaustralia.gov.au/publications/files/Cycling Infrastructure Back ground Paper 16Mar09 WEB.pdf.

8. Wood T, Milne P. Head injuries to pedal cyclists and the promotion of helmet use in Victoria, Australia. Accid Anal Prev. Jun 1988;20(3):177-185.

9. Vulcan AP, Cameron MH, Watson WL. Mandatory bicycle helmet use: experience in Victoria, Australia. (Abstract) World J Surg. May-Jun 1992;16(3):389-397.

10. McDermott FT. Helmet efficacy in the prevention of bicyclist head injuries: Royal Australasian College of Surgeons initiatives in the introduction of compulsory safety helmet wearing in Victoria, Australia. (Abstract) World J Surg. May-Jun 1992;16(3):379383.

11. McDermott FT, Lane JC, Brazenor GA, Debney EA. The effectiveness of bicyclist helmets: a study of 1710 casualties. (Abstract) J Trauma. Jun 1993;34(6):834-844; discussion 844-835.

12. Cameron MH, Vulcan AP, Finch CF, Newstead SV. Mandatory bicycle helmet use following a decade of helmet promotion in Victoria, Australia--an evaluation. (Abstract) Accid Anal Prev. Jun 1994;26(3):325-337.

13. McDermott FT. Bicyclist head injury prevention by helmets and mandatory wearing legislation in Victoria, Australia. Ann R Coll Surg Engl. Jan 1995;77(1):38-44.

14. Macpherson A, Spinks A. Bicycle helmet legislation for the uptake of helmet use and prevention of head injuries. Cochrane Database Syst Rev. 2008(3):CD005401. 
15. Krag T. European Cyclists' Federation. Bicycle helmet laws. June 2005. Available at: http://zakka.dk/cykelhjelm/cykelhjelm org 050615 helmet summary.pdf.

16. Thompson DC, Rivara FP, Thompson R. Helmets for preventing head and facial injuries in bicyclists. Cochrane Database Syst Rev. 2000(2):CD001855.

17. Attewell RG, Glase K, McFadden M. Bicycle helmet efficacy: a meta-analysis. Accid Anal Prev. May 2001;33(3):345-352.

18. Curnow WJ. The Cochrane Collaboration and bicycle helmets. Accid Anal Prev. May 2005;37(3):569-573.

19. Rietveld P, Daniel V. Determinants of bicycle use: do municipal policies matter? Transportation Research Part A: Policy and Practice. 2004;38(7):531-550.

20. Bauman A. RC, Garrard J., Ker I., Speidel R., Fishman E. Cycling: getting Australia moving barriers, facilitators and interventions to get more Australians physically active through cycling. 2008;

http://www.atrf.info/papers/2008/2008 Bauman Rissel Garrard Ker Spiedel Fishman.p df.

21. Pucher J, Dill J, Handy S. Infrastructure, programs, and policies to increase bicycling: an international review. Prev Med. Jan 2010;50 Suppl 1:S106-125.

22. Baker SP, O'Neill B, Haddon W, Jr., Long WB. The injury severity score: a method for describing patients with multiple injuries and evaluating emergency care. $J$ Trauma. Mar 1974;14(3):187-196.

23. Bureau of Statistics. Population by age, gender and region 2009. The Hague/Heerlen, The Netherlands. Updated May 2011. Available at: http://statline.cbs.nl/StatWeb/publication/?DM=SLNL\&PA=03759ned\&D1=0\&D2=129132\&D3=682\&D4=20-21\&HDR=T\&STB=G2\%60,G1\%60,G3\&VW=T.

24. Champion HR, Copes WS, Sacco WJ, et al. The Major Trauma Outcome Study: establishing national norms for trauma care. J Trauma. Nov 1990;30(11):1356-1365.

25. Bureau of Statistics. Population by age and sex, Australian states and territories. Canberra, Australia. 2009 (Catalogue No. 3235.2000). Available at: http://www.abs.gov.au/ausstats.

26. Cameron PA, Gabbe BJ, McNeil JJ, et al. The trauma registry as a statewide quality improvement tool. J Trauma. Dec 2005;59(6):1469-1476.

27. Association for the Advancement of Automotive Medicine: The Abbreviated Injury Scale 1990 Revision - Update 98. Barrington, IL: Association for the Advancement of Automotive Medicine. 1998.

28. Hirasing RA, Verloove-Vanhorick SP, van Kampen LT. [Bicycle accidents in children in The Netherlands in 1990/1991; time for bicycle helmets] (Abstract)

Fietsongevallen bij kinderen in Nederland in 1990/1991; tijd voor fietshelmen. Ned Tijdschr Geneeskd. Nov 12 1994;138(46):2315-2318. 
29. Acton CH, Thomas S, Nixon JW, Clark R, Pitt WR, Battistutta D. Children and bicycles: what is really happening? Studies of fatal and non-fatal bicycle injury. Inj Prev. Jun 1995;1(2):8691.

30. Vulcan P, Lane J. Bicycle helmets reduce head injuries and should be worn by all. Inj Prev. Dec 1996;2(4):251-252.

31. Thompson DC, Patterson MQ. Cycle helmets and the prevention of injuries. Recommendations for competitive sport. Sports Med. Apr 1998;25(4):213-219.

32. Ritter $\mathrm{N}$, Vance $\mathrm{C}$. The determinants of bicycle helmet use: evidence from Germany. Accid Anal Prev. Jan 2011;43(1):95-100.

33. Gutsche J, Hintzpeter B, Neuhauser H, Schlaud M. [Prevalence of helmet use in children and adolescents in Germany and preventable bicycle-related head injuries]

Helmtragequoten bei Kindern und Jugendlichen in Deutschland und vermeidbare Kopfverletzungen bei Fahrradunfallen. Gesundheitswesen. Aug 2011;73(8-9):491-498.

34. Berg $P$, Westerling $R$. A decrease in both mild and severe bicycle-related head injuries in helmet wearing ages--trend analyses in Sweden. Health Promot Int. Sep 2007;22(3):191197.

35. Airaksinen N, Luthje $P$, Nurmi-Luthje I. Cyclist Injuries Treated in Emergency Department (ED): Consequences and Costs in South-eastern Finland in an Area of $\mathbf{1 0 0} 000$ Inhabitants. Ann Adv Automot Med. 2010;54:267-274.

36. Scheiman S, Moghaddas HS, Bjornstig U, Bylund PO, Saveman BI. Bicycle injury events among older adults in Northern Sweden: a 10-year population based study. Accid Anal Prev. Mar 2010;42(2):758-763.

37. Kingma J. The aetiology of bicycle accidents. Percept Mot Skills. Dec 1994;79(3 Pt 1):11931194.

38. Austroads Research Report: Cycling on Higher Speed Roads. Sydney, Australia. July 2012. Available at: http://btawa.org.au/wp-content/uploads/2012/07/Cycling-on-Higher-SpeedRoads-Gardner-Eady-and-Daff-Austroads-2012.pdf.

39. SWOV, Institute for Road Safety Research. Advancing Sustainable Safety: National Road Safety Outlook for 2005-2020. Leidschendam, The Netherlands. 2006. Available at: http://www.swov.nl/rapport/DMDV/Advancing Sustainable Safety.pdf. 
Table 1. Bicycle-related major trauma with ISS $>15$ and Age $\geq 15$ : Netherlands trauma centre, Rotterdam, The Netherlands vs. Australian trauma centre,

Melbourne, Australia (July 2001-June 2009)

\begin{tabular}{|c|c|c|c|c|}
\hline & & $\begin{array}{l}\text { Netherlands } \\
\text { trauma centre } \\
(\mathrm{n}=187)\end{array}$ & $\begin{array}{l}\text { Australian } \\
\text { trauma centre } \\
(\mathrm{n}=194)\end{array}$ & p-value \\
\hline \multirow[t]{7}{*}{ Age group $^{1}$} & 15-19 years & $19(10.2)$ & $20(10.3)$ & $<0.001$ \\
\hline & $20-29$ years & $16(8.6)$ & $19(9.8)$ & \\
\hline & 30-39 years & $11(5.9)$ & $36(18.6)$ & \\
\hline & $40-49$ years & $19(10.2)$ & $40(20.6)$ & \\
\hline & $50-59$ years & $31(16.6)$ & $46(23.7)$ & \\
\hline & $60-69$ years & $46(24.6)$ & $21(10.8)$ & \\
\hline & $70+$ years & $45(24.1)$ & $12(6.2)$ & \\
\hline Gender $^{1}$ & Male & $112(59.9)$ & $167(86.1)$ & $<0.001$ \\
\hline \multirow{7}{*}{$\begin{array}{l}\text { Mechanism of } \\
\text { injury }{ }^{1, a}\end{array}$} & Car & $101(54.6)$ & $77(41.0)$ & $<0.001$ \\
\hline & Fall & $32(17.3)$ & $64(34.0)$ & \\
\hline & Obstacle & $8(4.3)$ & $17(9.0)$ & \\
\hline & Bicycle & $7(3.8)$ & $12(6.4)$ & \\
\hline & Truck & $13(7.0)$ & $6(3.2)$ & \\
\hline & Tram & $8(4.3)$ & $3(1.6)$ & \\
\hline & Other & $16(8.7)$ & $9(4.8)$ & \\
\hline Helmet worn ${ }^{1, b}$ & Yes & $1(4.5)$ & $47(72.3)$ & $<0.001$ \\
\hline \multirow[t]{3}{*}{ GCS on arrival ${ }^{1, c}$} & $3-8$ & $79(44.1)$ & $45(23.6)$ & $<0.001$ \\
\hline & $9-12$ & $23(12.9)$ & $5(2.6)$ & \\
\hline & $13-15$ & $77(43.0)$ & $141(73.8)$ & \\
\hline $\operatorname{ISS}^{2, *}$ & & $22(17-29)$ & $22(18-29)$ & 0.594 \\
\hline \multirow[t]{3}{*}{ AIS Head/Neck ${ }^{1}$} & $0-2$ & $22(11.8)$ & $73(37.6)$ & $<0.001$ \\
\hline & $3-4$ & $119(63.6)$ & $95(49.0)$ & \\
\hline & $5-6$ & $46(24.6)$ & $26(13.4)$ & \\
\hline \multirow[t]{3}{*}{ AIS Facial $^{1}$} & 0 & $105(56.1)$ & $133(68.6)$ & $<0.001$ \\
\hline & 1 & $37(19.8)$ & $11(5.7)$ & \\
\hline & $\geq 2$ & $45(24.1)$ & $50(25.8)$ & \\
\hline \multirow[t]{2}{*}{ AIS Chest $^{1}$} & $\overline{0}-2$ & $131(70.1)$ & $93(47.9)$ & $<0.001$ \\
\hline & $\geq 3$ & $56(29.9)$ & $101(52.1)$ & \\
\hline \multirow[t]{2}{*}{ AIS Abdominal $^{1}$} & $0-2$ & $177(94.6)$ & $172(88.7)$ & 0.035 \\
\hline & $\geq 3$ & $10(5.4)$ & $22(11.3)$ & \\
\hline \multirow[t]{3}{*}{ AIS Extremity $^{1}$} & $0-1$ & $118(63.1)$ & $89(45.9)$ & 0.003 \\
\hline & 2 & $44(23.5)$ & $63(32.5)$ & \\
\hline & $\geq 3$ & $25(13.4)$ & $42(21.6)$ & \\
\hline \multirow{5}{*}{$\begin{array}{l}\text { Hospital discharge } \\
\text { destination }{ }^{1, \mathrm{~d}} \\
\text { (survivors to } \\
\text { discharge) }\end{array}$} & & & & $<0.001$ \\
\hline & Home & 77 (41.6) & $98(50.5)$ & \\
\hline & $\begin{array}{l}\text { Inpatient } \\
\text { rehabilitation }\end{array}$ & $18(9.7)$ & $83(42.8)$ & \\
\hline & $\begin{array}{l}\text { Hospital for } \\
\text { convalescence }\end{array}$ & $30(16.2)$ & $0(0.0)$ & \\
\hline & Other & $15(8.1)$ & $0(0.0)$ & \\
\hline
\end{tabular}




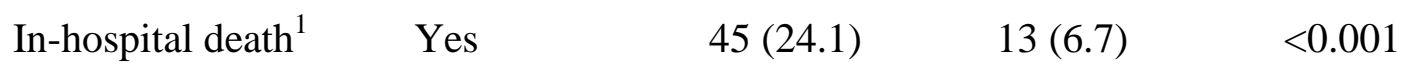

${ }^{1}$ Data displayed as number of patients and percentages n $(\%)$

${ }^{2}$ Data displayed as median with first and third quartile

${ }^{a}$ Data missing for $n=2$ Netherlands trauma centre cases and $n=6$ Australian trauma centre cases

${ }^{\mathrm{b}}$ Data missing for $\mathrm{n}=165$ Netherlands trauma centre cases and $n=129$ Australian trauma centre cases

${ }^{c}$ Data missing $n=8$ Netherlands trauma centre cases and $n=3$ Australian trauma centre cases

${ }^{\mathrm{d}}$ Data missing for $\mathrm{n}=2$ Netherlands trauma centre cases and $\mathrm{n}=0$ Australian trauma centre cases

GCS= Glasgow Coma Score; ISS= Injury Severity Score; AIS= Abbreviated Injury Score

Chi-square test comparing Rotterdam and Victoria with $P$ value $<0.05$.

* Mann-Whitney U test calculated and median (Inter-Quartile Range) with $P$ value $<$ 0.05 . 


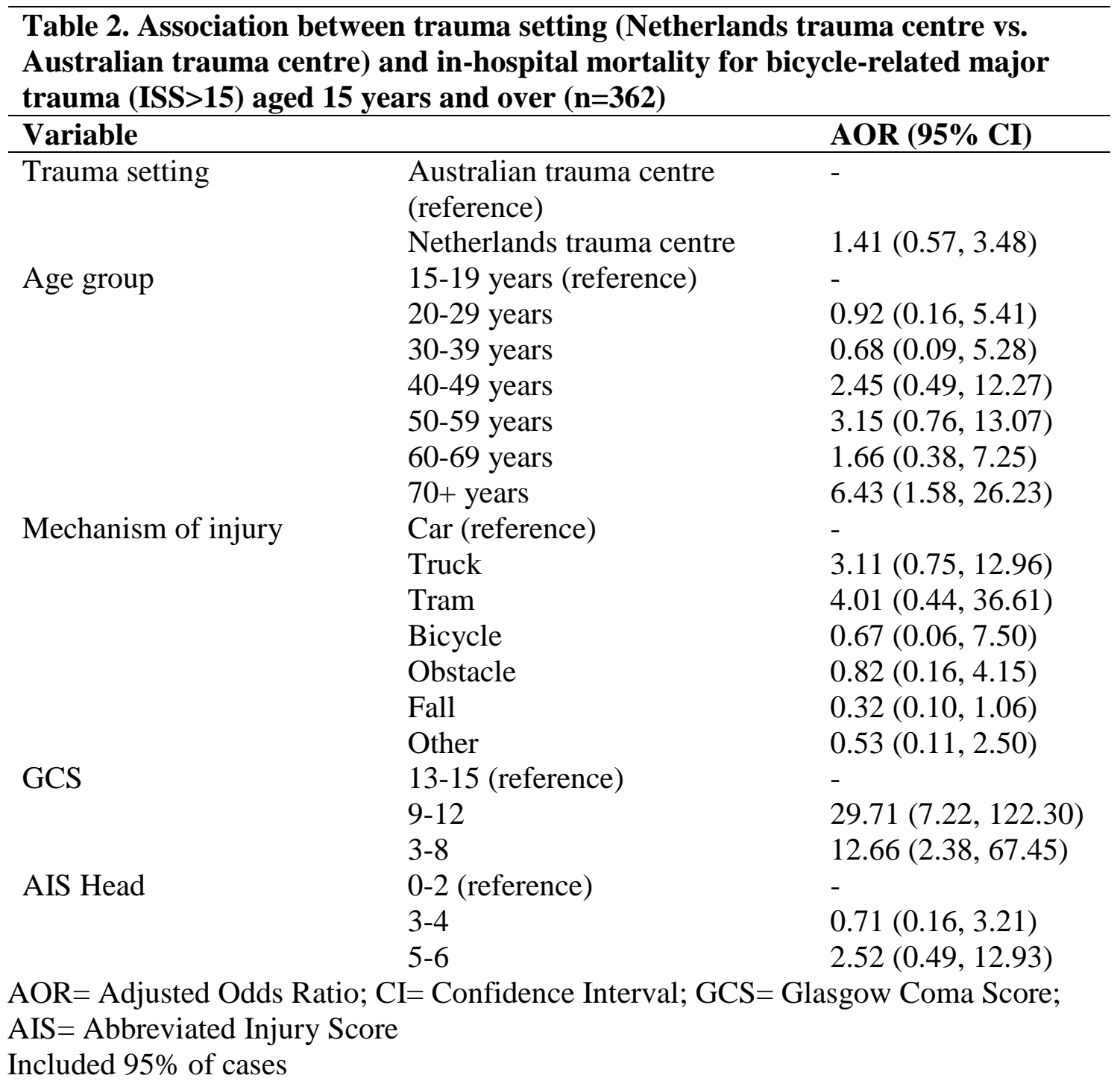


Figure 1: Region South West Netherlands with Netherlands trauma centre and State of Victoria with Australian trauma centre: population of serious trauma patients due to bicycle accidents (Injury Severity Score>15)

South West Netherlands

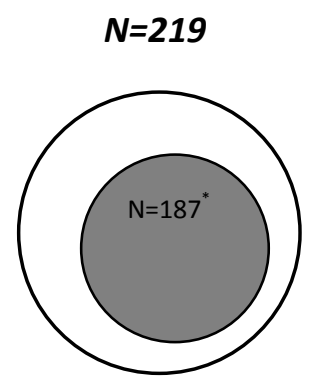

*Netherlands trauma centre
State of Victoria

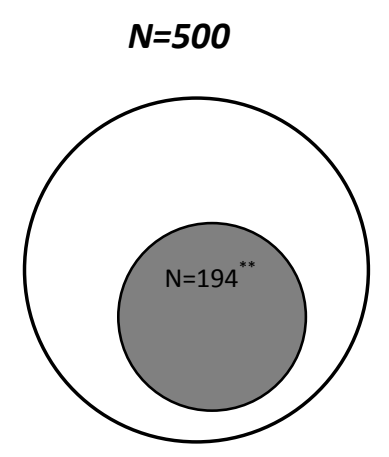

**Australian trauma centre 
Figure 2: Bicycle related head injury cases in Netherlands trauma centre

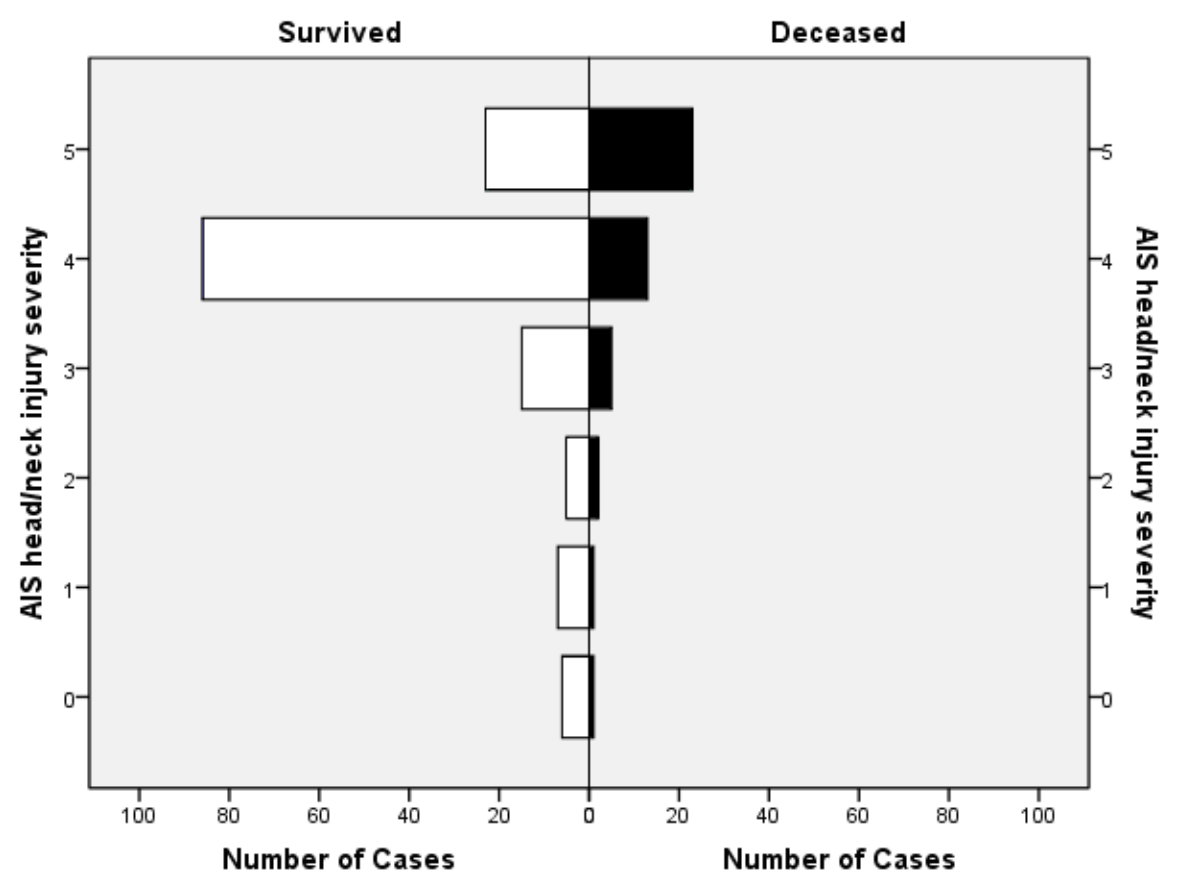


Figure 3: Bicycle related head injury cases in Australian trauma centre

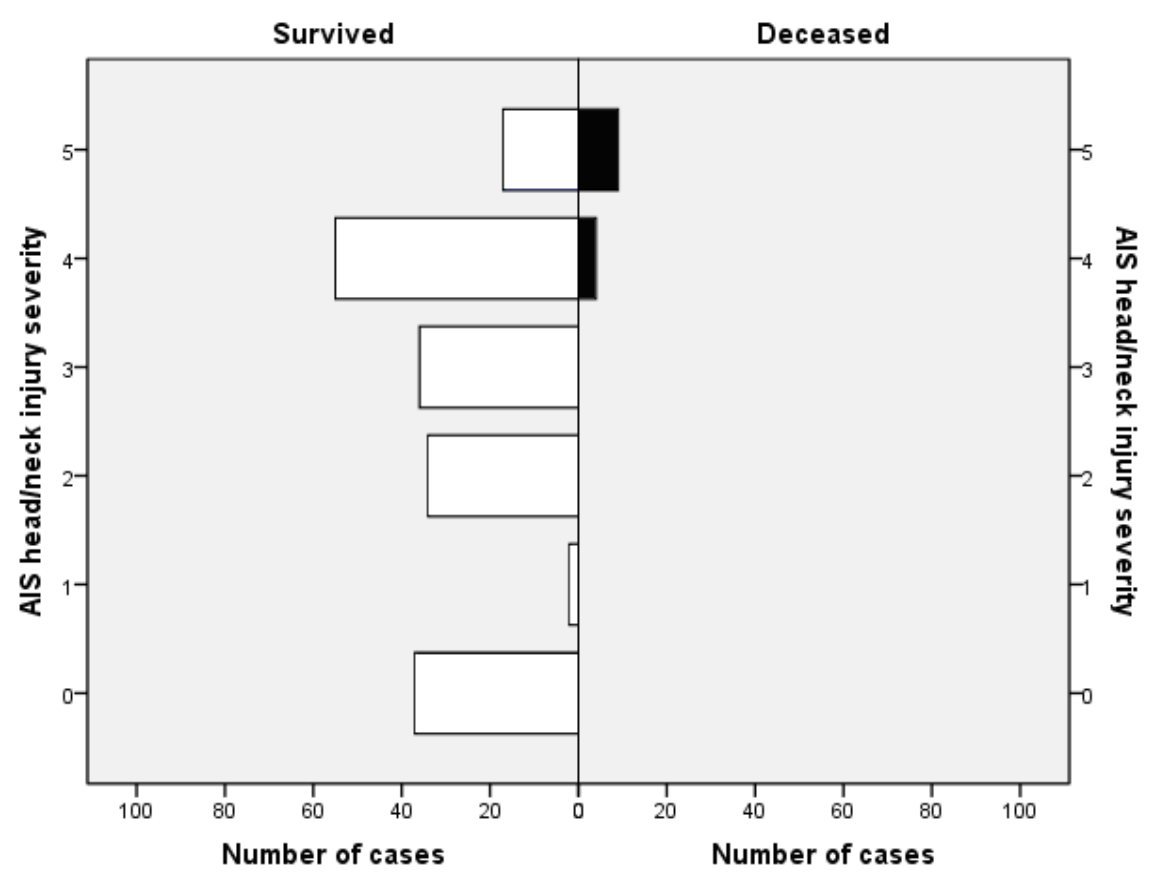




\section{Conflict of interest statement}

On behalf of all authors, I confirm that the research reported in this manuscript has no conflicts of interest involved and has not received any financial support nor has been accomplished for organisations or other personal relationships with other people. 